\title{
OČUVANOST AUTENTIČNE GASTRONOMIJE VOJVOĐANSKIH SLOVAKA U CILJU RAZVOJA TURIZMA
}

\author{
Bojana Kalenjuk, \\ Maja Banjac, \\ Bojan Đerčan, \\ Biljana Cvetković
}

Prirodno-matematički fakultet, Novi Sad, Srbija

\begin{abstract}
Rezime:
Istorijska dešavanja na teritoriji Vojvodine i struktura stanovništva u mnogome su doprineli formiranju gastronomskog identiteta ovog regiona. Vojvodina predstavlja multikulturalno područje koje naseljava preko trideset nacionalnih manjina. Prema popisu stanovništva posle Mađara, Slovaci predstavljaju drugu po brojnosti etničku grupu u Vojvodini. Gastronomija Slovaka ruralnih područja (kao nematerijalno kulturno nasleđe) je prepoznata kao važan resurs razvoja lokalne zajednice kroz sve oblike turizma, ali posebno kroz razvoj gastronomskog turizam. Iz tog razloga mesto istraživanja u radu su ruralna područja Vojvodine koja naseljavaju Slovaci. Zadatak rada je da dođe do saznanja u kojoj meri stanovnici vojvođanskih sela neguju identitet i autentičnosti svoje kuhinje, kroz proizvodnju poljoprivrednih i prehrambenih proizvoda i pripremu jela. Cilj istraživanje je da se ispita da li slovačko stanovništvo valorizuje svoje kulturno gastronomsko nasleđe, koje može biti iskorišćeno u cilju razvoja turizma regiona. Istraživanje je sprovedeno anketiranjem lokanog stanovništva putem struktuiranog upitnika. Dobijeni podaci su statistički obrađeni. Istraživanje je pokazalo da vojvođanski Slovaci unutar ruralnih područja neguju svoju gastronomsku kulturu i tradiciju kroz proizvodnju određenih grupa poljoprivrednih i prehrambenih proizvoda i pripremu različitih autentičnih specijaliteta. Autentična hrana kao ključni segment u razvoju turizma u analiziranim vojvođanskim područjima u potpunosti se može iskoristiti za razvoj turizma.
\end{abstract}

Ključne reči:

hrana, ishrana, Slovaci, ruralna područja, turizam hrane

UVOD

Vojvodina je multikulturalni region koji objedinjuje veliki broj kuhinja (Ivkov, 2004). Raznolikost etničkih grupa utiče na formiranje ponude koja ima veliki uticaj na razvoj turizma (Kalenjuk et al., 2018a). U svetu se velika pažnja posvećuje ponudi hrane pored različitih oblika turizma (Baum, 2011; Kalenjuk et al., 2012). Naseljavanje velikog broja različitih etničkih grupa koje su sa sobom donele i svoje načine u pripremanju jela uticalo je da Vojvodina preraste $\mathrm{u}$ pogodnu destinaciju za razvijanje turizma hrane (Kalenjuk et al., 2017; Kalenjuk et al., 2018b). Turisti su sve više zainteresovani za načine pripremanja autentičnih jela i rado se opredeljuju za škole kuvanja (Hall and Mitchell, 2006). U fokusu interesovanja pored raznovrsnih ponuda unutar različitih metropola su ruralna područja (Baum, 2011;
Correspondence:

Bojana Kalenjuk

e-mail:

bojana.kalenjuk@dgt.uns.ac.rs 
Kalenjuk et al., 2014; Vuksanović et al., 2016). Ova područja predstavljaju lokalitete sa sačuvanom autentičnom gastronomskom tradicijom (Banjac et al., 2016). Turizam predstavlja deo privrede koja ima izraženu društvenu i ekonomsku funkciju i pomaže u valorizaciji poljoprivrednog regiona (Henderson, 2004; Quan and Wang, 2004; Gagic et al., 2014). Zahvaljujući autentičnim jelima očuvanih u ruralnim područjima posetioci upoznaju kulturu i običaje destinacije. Svetske turističke organizacije su prepoznale potencijale gastronomije određenih regiona i stavile ih u svoju turističku ponudu, kao deo: turizama hrane, gastronomskog turizma, kulinarskog turizma i degustacionog ili gurmanskog turizma (Hjalager and Richards, 2002; Boniface, 2003; Wolf, 2006; Ignatov and Smith, 2006).

Vojvodina predstavlja reprezentativni turistički prostor koji naseljava oko trideset nacija, tačnije 35\% od ukupne populacije (Kalenjuk, 2017), od kojih posle mađarskog stanovništva koje čini čak 13\%, Slovaci zauzimaju 2,6\%. Po popisu iz 2011. godine Vojvodinu naseljava 50321 pripadnik slovačke etničke grupe (Bubalo-Živković, 2017). Zahvaljujući istorijskim dešavanjima na teritoriji Vojvodine uticalo se na formiranje različitih oblika specifičnosti, koji su zajedno sa plodnom ravnicom uticali i na formiranje bogate i raznolike gastronomije (Banjac et al., 2016). Način ishrane predstavlja odraz brojnih faktora, pa se zbog uticaja brojnih činilaca često razlikuje od mesta do mesta, pa čak i među domaćinstvima unutar istih naselja (Stojanović and Čerović, 2008) ali često i unutar etničkih grupa.

Predmet istraživanja je sačuvanost gastronomije Slovaka koji naseljavaju Vojvodinu. Zadatak istraživanja je da dođe do podataka o autentičnosti kuhinje Slovaka i mogućnostima ponude jedinstvenog gastronomskog iskustva u ugostiteljstvu i turizmu. Cilj rada je dođe do odgovora na postavljena istraživačka pitanja:

- Koje biljne vrste uzgajaju vojvođanski Slovaci?

- Koje prehrambene proizvode u svojim domaćinstvima proizvode?

- Da li i koliko pripremaju jela po tradicionalnim recepturama?

- Kolika je očuvanost autentičnih jela u njihovim domaćinstvima, domaćinstvu njihovih potomaka i sunarodnika?

- Koja jela su predstavnici slovačke kuhinje i koja jela od sunarodnika i oni pripremaju?

\section{METODOLOGIJA RADA}

Istraživanje je sprovedeno pomoću upitnika u seoskim naseljima Vojvodine koja naseljava Slovačka nacionalna manjina, a to su sledeće opštine: Bački Petrovac, Kovačica, Zrenjanin, Alibunar, Bač, Plandište, Stara Pazova i Šid. Fokusna grupa su bili stanovnici stariji od 50 godina. U cilju dobijanja što reprezentativnijih podataka sakupljeno je 140 anketa od kojih su iskorišćene i statistički obrađene 104 ankete. Dobijeni podaci su obrađeni primenom deskriptivne statistike, a potom u radu prikazani tabelarno i grafički.

\section{REZULTATI RADA I DISKUSIJA}

\section{Analiza socio-demografskih karakteristika ispitanika}

Od ukupnog uzorka u istraživanju je učestvovalo $66,7 \%$ ispitanika ženskog pola, ostatak su bili pripadnici muškog pola. Najveći udeo su činili ispitanici starosti između 51-60 godina sa 65,4\%, a ostatak ispitanika činile su grupe od 61-70 godina i preko 70 godina sa po 17,3\%. Po strukturi obrazovanja među ispitanicima je učestvovalo ukupno 51,9\% ispitanika sa završenom srednjom školom, 34,6\% ispitanika sa završenom osnovnom školom i samo 13,5\% sa završenom visokom školom ili fakultetom. Najveći broj ispitanika činili su penzioneri sa $40,4 \%$, slede ih sa $30,8 \%$ sa statusom u radnom odnosu i na kraju bez radnog odnosa, nezaposleni sa $20,8 \%$. Kako bi se stekao uvid u kućni budžet, koji može biti povezan sa načinom dobijanja hrane (samostalna proizvodnja) istražena su primanja po članu domaćinstva. Najveći procenat ispitanika imao je prosečna primanja od 20,000 do 40,000 din sa udelom od 53,8\%, primanja do 20,000 din imalo je 25\%, i najmanji procenat ispitanika $21,2 \%$ imao je najveća primanja od preko 40,000 din (tabela 1 ). 
Istraživanjem samostalne proizvodnje hrane, utvrđeno je da $87 \%$ ispitanika uzgaja povrće, ali i $83 \%$ različite sorte voća. Životinje iz grupe stoke za klanje uzgaja 48\% ispitanika, takođe i pernate živine uzgaja sličan procenat anketiranih unutar svojih domaćinstava 50\%. Životinje za dobijanje mleka uzgaja 17\% ispitanika, a povremeno samo $10 \%$, što je ukupno jako malo, dok živinu za dobijanje jaja uzgaja 30\% ispitanika i 30\% privremeno. Žitarice uzgaja 50\% ispitanika, a 57\% se bavi samostalnim uzgojem začinskog bilja (peršun, mirođija, celer i dr.), dok lekovito (nana, kantarion i dr.) uzgaja jako mali udeo domaćinstava, samo iz 4\% ispitanih (grafikon 1).

Prema dobijenim rezultatima koji su prikazani u grafikonu 2 može se videti da $81 \%$ ispitanika samostalno obrađuje povrće za dobijanje zimnice, a $86 \%$ ispitanika samostalno priprema različite vrste džema, pekmeza, marmelade, slatkog, sokova i dr. proizvoda na bazi voća. Dimljene suvomesnate proizvode proizvodi samostalno $42 \%$ ispitanika, a kobasice $57,5 \%$ domaćinstava. Proizvodnjom sira bavi se $17 \%$ ispitanika, dok se fermentisanim mlečnim proizvodima ne bavi nijedno domaćinstvo, što je pomalo začuđujući podatak. Proizvodnjom hleba i sličnim pekarskim proizvodima bavi se $19 \%$ ispitanika. Pića kao što su rakije i vina, unutar svojih domaćinstava proizvodi 12,5\% ispitanika, a povremeno 56\% ispitanika (grafikon 2).

Tabela 1. Socio-demografska struktura zaposlenih

\begin{tabular}{|c|c|c|c|}
\hline & & $\mathbf{n}$ & Procenat \\
\hline \multicolumn{4}{|l|}{ Pol } \\
\hline Muško & & 35 & 33,3 \\
\hline \multirow[t]{2}{*}{ Žensko } & & 69 & 66,7 \\
\hline & Ukupno & 104 & 100 \\
\hline \multicolumn{4}{|l|}{ Obrazovanje } \\
\hline \multicolumn{2}{|l|}{ Osnovna škola } & 36 & 34,6 \\
\hline \multicolumn{2}{|l|}{ Srednja škola } & 54 & 51,9 \\
\hline \multicolumn{2}{|l|}{ Visoka škola, fakultet } & 14 & 13,5 \\
\hline & Ukupno & 104 & 100 \\
\hline \multicolumn{4}{|l|}{ Starost } \\
\hline \multicolumn{2}{|l|}{$51-60$} & 68 & 65,4 \\
\hline \multicolumn{2}{|l|}{$61-70$} & 18 & 17,3 \\
\hline \multicolumn{2}{|l|}{ Preko 70} & 18 & 17,3 \\
\hline & Ukupno & 104 & 100 \\
\hline \multicolumn{4}{|l|}{ Status } \\
\hline \multicolumn{2}{|l|}{ U radnom odnosu } & 32 & 30,8 \\
\hline \multicolumn{2}{|l|}{ Nezaposlen } & 30 & 28,8 \\
\hline \multicolumn{2}{|l|}{ Penzioner } & 42 & 40,4 \\
\hline & Ukupno & 104 & 100 \\
\hline \multicolumn{4}{|l|}{ Prosečna primanja u domaćinstvu } \\
\hline \multicolumn{2}{|l|}{ Do 20,000 din } & 26 & 25 \\
\hline \multicolumn{2}{|l|}{ Od 20,000 do 40,000 din } & 56 & 53,8 \\
\hline \multicolumn{2}{|l|}{ Preko 40,000 din } & 22 & 21,2 \\
\hline & Ukupno & 104 & 100 \\
\hline
\end{tabular}

Izvor: istraživanje autora 
Grafikon 1. Samostalno uzgajanje biljnih i životinjskih vrsta

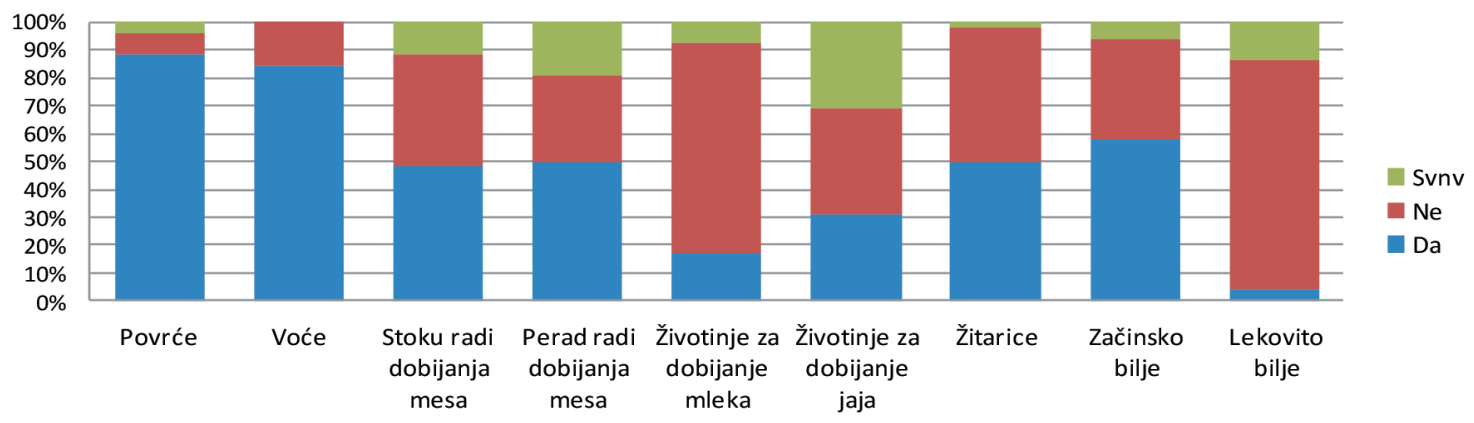

Izvor: Istraživanje autora

Grafikon 2. Samostalna proizvodnja prehrambenih proizvoda

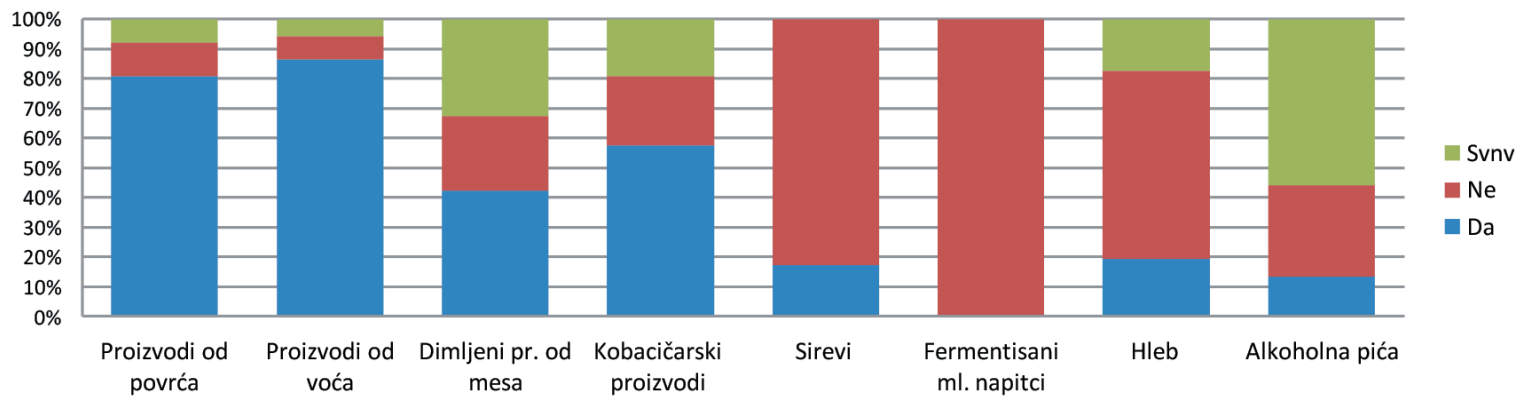

Izvor: Istraživanje autora

\section{Analiza pripreme jela po tradicionalnim recepturama}

Jedan od najbitnijih segmenata za razvoj turizma jeste očuvanost autentičnih načina pripreme jela. Nivo očuvanosti tradicionalnih receptura Slovaka prikazan je u grafikonu 3. Iz dobijenih podataka može se konstatovati da niko od ispitanika ne priprema sva hladna predjela, sva topla predjela kao i sva jela od ribe po svojim tradicionalnim recepturama. Isključivo slovačke supe i čorbe priprema $10 \%$ ispitanika, takođe je slično kod pripremanja jela od crvenih mesa $10 \%$, pripremanja jela od mesa peradi čak $11 \%$, salata i sosova po $10 \%$. Na osnovu dobijenih podataka može se konstatovati veći udeo jela od testa, čak $28 \%$ ispitanika, deserata reprezentativnih $63 \%$ i $27 \%$ ispitanika priprema svu zimnicu po slovačkim tradicionalnim recepturama.

Grafikon 3. Priprema jela po tradicionalnim recepturama

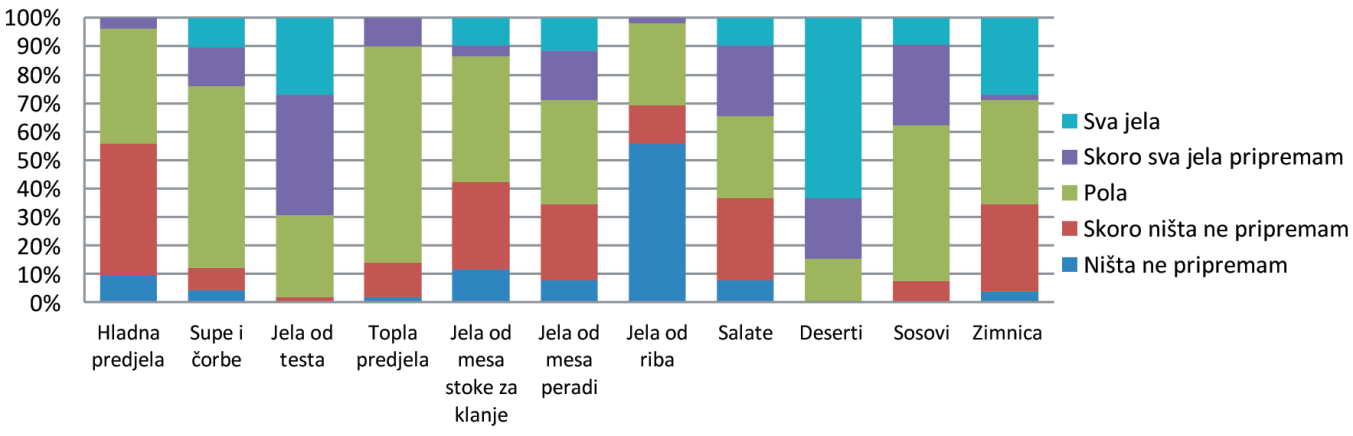


Posmatrano u celini (grafikon 4) u proseku samo 16\% slovačkih domaćinstava iz istraživanja priprema skoro sva jela po starim recepturama, $15 \%$ ispitanika priprema skoro sva jela i $42 \%$ polovinu jela, na čemu se može poraditi ako bi se ista dodatno plasirana u ponudi zarad privlačenja turista.

Grafikon 4. Ukupna priprema jela po autentičnim recepturama

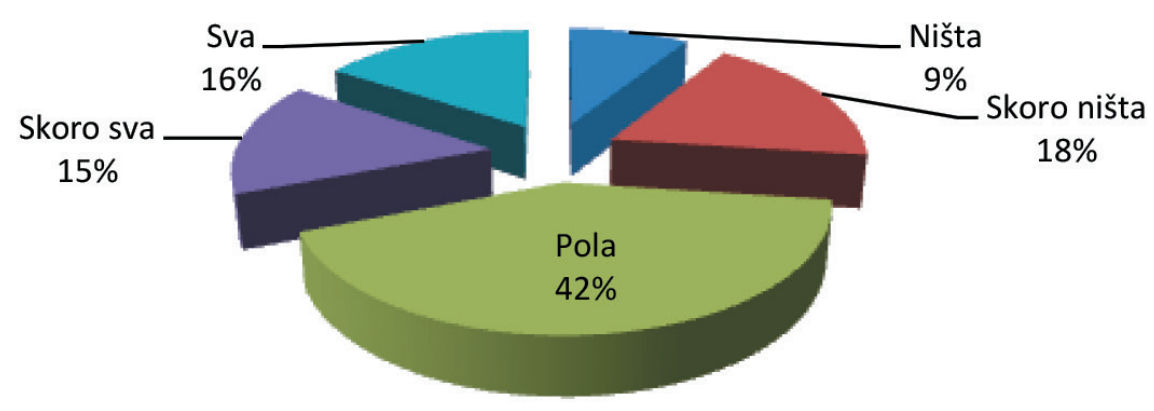

Izvor: Istraživanje autora

\section{Analiza očuvanosti pripreme jela i usvajanja novih}

U cilju dolaska do podataka o očuvanosti autentičnih slovačkih jela ispitanicima je dato da je putem skale u rasponu od 1 do 10 ocene. Najvišu srednju ocenu 6,48 anketirani su dali pripremi autentičnih jela u domaćinstvima svojih sunarodnika, sa ocenom 5,25 ocenili su pripremu autentičnih jela u domaćinstvu svojih potomaka i sa srednjom ocenom 5,52 ocenjena je očuvanost autentičnih jela u svom domaćinstvu. Dalje u istraživanju ispitanici su se izjašnjavali koja jela smatraju predstavnicima njihove kuhinje, zatim po čemu se njihova kuhinja razlikuje od gastronomije drugih naroda u okruženju i koje segmente su usvojili iz okoline a da nisu autentični za njihovu kuhinju.

Jela koja smatraju predstavnicima njihove kuhinje su: knedle sa džigericom, tašci, valjušci sa sirom, opekance, stropačkky, hrenovke, kukuruzni uštipci, suštovnika, hleb sa kimom, bryndzove, pirohe, bryndzove halusky, kim čorba, rosčovka, buchty, kupusnjike, ciblinova juha, domaći rezanci sa sirom, šuštovnika. Na pitanje po čemu se razlikuje njihova kuhinja od drugih naroda u okruženju svi ispitanici su jednoglasno istakli da je velika i česta upotreba začina, kombinacija slatko-slanih ukusa u jednom jelu (jela na bazi kompota i mesa), obimna konzumacija jela od testenine i visoka kalorijska vrednost jela. Odgovorom na pitanje koje segmente iz okoline su usvojili došlo se do saznanja da su ispitanici najviše usvojili raznovrsna jela od usitnjenog mesa, jela sa roštilja, jela od povrća i deserte.

\section{ZAKLJUČAK}

Istraživajući nivo očuvanosti kuhinje vojvođanskih Slovaka koji naseljavaju seoska područja, u cilju da se dođe do podataka o mogućnosti ponude autentične gastronomije u turizmu, uz primenu odgovarajuće metodologije došlo se do zaključka da Slovačko stanovništvo u najvećoj meri samostalno uzgaja voće i povrće, ali i proizvode određene vrste prehrambenih proizvoda karakterističnih za svoju grupu, gde značajno mesto sa razlogom zauzimaju kobasičarski proizvodi. Najveća očuvanost je uočena kod pripreme deserta i jela od testa, a istraživana etnička grupa pravim predstavnicima svoje kuhinje smatraju: knedle sa džigericom, taške, valjuške sa sirom, opekance, stropačkky, hrenovke, kukuruzne uštipke, suštovnika, hleb sa kimom, bryndzove, bryndzove halusky, kim čorba, rosčovka, buchty, kupusnjike, ciblinova juha, šuštovnika i dr. Sva ova jela mogu se impementirati u turističku ponudu. Pored svojih jela Slovaci su usvojili recepture pripreme jela od svojih sunarodnika i to je sa razlogom karakteristično za mlađu populaciju. U cilju razvoja turizma usmerenog na autentičnu hranu, na održivosti očuvanih gastronomskih segmenata treba dodatno poraditi i uvrstiti ih ponudu ugostiteljskih objekata, čime bi uticalo na navike potražnje stanovništva koje je odavno zaboravilo ove autentične ukuse. 


\section{ZAHVALNOST}

Rezultati predstavljeni u radu su deo projekta koji je finansiran od strane Pokrajinskog sekretarijata za visoko obrazovanje i naučnoistraživačku delatnost, pod nazivom „Antropogeografske i kulturne vrednosti vojvođanskih Slovaka kao faktor održivosti nacionalnog identiteta“, 142-451-2686/2018-01.

\section{LITERATURA}

Banjac, M., Kalenjuk, B., Tešanović, D., Gagić, S. \& Cvetković, B. (2016). Gastronomic Tourism in Rural Areas of Vojvodina (Serbia). Turizam, 20(4), 180-191. DOI:10.18421/TRZ20.04-02

Baum, S. (2011). The Tourist Potential of Rural Areas in Poland. Eastern European Countryside, 17, 107-135. DOI:10.2478/V10130-011-0006-Z

Boniface, P. (2003). Tasting Tourism: Travelling for Food and Drink. Aldershot: Ashgate.

Bubalo-Živković, M. (2017). Starost etničkih grupa na prostoru Vojvodine. U monografiji pod nazivom: Etničke grupe Vojvodine u 21. veku - stanje i perspektive održivosti, (18-45). Novi Sad: PMF.

Gagić, S. Jovičić, A., Tešanović, D. \& Kalenjuk, B. (2014). Motives for food choice among serbian consumers. Economics of Agriculture, Belgrade, 61(1), 41-51. DOI:10.5937/ekoPolj1401041G

Hall, C.M. \& Mitchell, R. (2006). Gastronomy, food and wine tourism. In: Buhalis, D., Costa C., Tourism Business Frontiers - Consumers, products and industry, (137-147). Oxford: Elsevier Ltd.

Henderson, J.C. (2004). Food as a tourism resource: A view from Singapore. Tourism Recreation Research, 29(3), 69-74. DOI:10.1080/02508281.2004.11081459

Hjalager, A.-M. \& Richards, G. (2002). Tourism and Gastronomy. London: Routledge.

Ignatov, E. \& Smith, S. (2006). Segmenting Canadian culinary tourists. Current Issues in Tourism, 9(3), 235-255. DOI:10.2167/cit/229.0

Ivkov, A. (2004). Gastronomija Vojvodine kao faktor atraktivnosti njene turističke ponude. Hotellink, 3, 221227.

Kalenjuk, B., Cvetković, B., Tešanović, D., \& Banjac, M. (2018a). Gastronomic tourism in rural areas of Vojvodina (North Serbia) - Dispersion, condition and offer of authentic restaurants "messuages. World Scientific News (WSN), 100, 124-134. EISSN 2392-2192

Kalenjuk, B. (2017). Hrana i ishrana stanovništva Vojvodine u funkciji razvoja turizma, kao odraz ponude ugostiteljskih objekata. U monografiji pod nazivom: Etničke grupe Vojvodine u 21. Veku - stanje i perspektive održivosti, (129-144). Novi Sad: PMF.

Kalenjuk, B., Cvetković, B. \& Dević-Blanuša, J. (2017). Autentična hrana ruralnih područja Vojvodine i značaj za razvoj gastronomskog turizma. Turističko poslovanje, 20, 27-35.

Kalenjuk, B., Cvetković, B., Dević Blanuša, J., \& Lukić, T. (2018b). Authentic food of Hungarians in Vojvodina (North Serbia) and its significance for the development of food tourism. World Scientific News (WSN), 106, 151-162.

Kalenjuk, B., Đerčan, B., \& Tešanović, D. (2012). Gastronomy tourism as a factor of regional development. Ekonomika, 3, 136-146.

Kalenjuk, B., Tešanović, D. \& Gagić, S. (2014). Regional development of tourist destinations through the development of gastronomic tourism. In: Since the crisis on development, the 4th International Scientific Conference, 24, 2014 Octobar 2014 (pp. 363-374). BIH: University of Business Studies.

Quan, S. \& Wang, N. (2004). Towards a structural model of the tourist experience: an illustration from food experiences in tourism. Tourism Management, 25(3), 297-305. DOI: org/10.1016/S0261-5177(03)00130-4

Stojanović, T. \& Čerović, S. (2008). Gastronomic offer of rural tourism: Tourist attraction of geographic area of Serbia. Collection of papers, Faculty of Geography at the University of Belgrade, 56, 165-176.

Vuksanović, N., Tešanović, D., Kalenjuk, B., Portić, M. \& Kneženić, M. (2016). Socio-demographic characteristics as determinants of differences in perception of local gastronomy. Ekonomika poljoprivrede, 64(1), 359-373. DOI:10.5937/ekoPolj1701359V

Wolf, E. (2006). Culinary Tourism: The Hidden Harvest. Dubuque: Kendall/Hunt Publishing. 


\title{
PRESERVATION OF AUTHENTIC GASTRONOMY OF VOJVODINA SLOVAKS FOR THE PURPOSE OF TOURISM DEVELOPMENT
}

\begin{abstract}
:
The historical events on the territory of Vojvodina and the structure of population have contributed greatly to the formation of the gastronomic identity of this region. Vojvodina represents a multicultural area that is inhabited by over thirty national minorities. According to the population census, following the Hungarians, the Slovaks represent the second largest ethnic group in Vojvodina. The gastronomy of the Slovakian rural areas (as a non-material cultural heritage) has been recognized as an important resource for the development of the local community through all forms of tourism, especially through the development of gastronomic tourism. For this reason, the location of the research is the rural area of Vojvodina inhabited by the Slovaks. The purpose of the paper is to identify to what extent the residents of Vojvodina villages foster the identity and authenticity of their cuisine through the production of agricultural and food products and meal preparation. The aim of the paper is to examine whether the Slovakian population valorises its cultural gastronomic heritage, which can be used for the development of tourism in the region. The survey was conducted by interviewing the local population through a structured questionnaire. The obtained data was statistically processed. The research has shown that the Vojvodina Slovaks within rural areas foster their gastronomic culture and tradition through the production of certain groups of agricultural and food products and through preparation of various authentic specialties. As a key segment in the development of tourism in the analysed Vojvodina areas, their authentic food can be fully utilized for the development of tourism.
\end{abstract}

Keywords:

food, nutrition, Slovaks, rural areas, food tourism 